\title{
A meta-analysis of outcomes and complications of magnetic resonance-guided focused ultrasound in the treatment of essential tremor
}

\author{
Nasser Mohammed, MD, MCh, Devi Patra, MD, MCh, and Anil Nanda, MD, MPH \\ Department of Neurosurgery, Louisiana State University Health Sciences Center, Shreveport, Louisiana
}

OBJECTIVE Magnetic resonance-guided focused ultrasound (MRgFUS) is a novel technique that uses high-intensity focused ultrasound to achieve target ablation. Like a lens focusing the sun's rays, the ultrasound waves are focused to generate heat. This therapy combines the noninvasiveness of Gamma Knife thalamotomy and the real-time ablation of deep brain stimulation with acceptable complication rates. The aim of this study was to analyze the overall outcomes and complications of MRgFUS in the treatment of essential tremor (ET).

METHODS A meta-analysis in accordance with the Preferred Reporting Items for Systematic Reviews and MetaAnalyses (PRISMA) guidelines was made by searching PubMed, Cochrane library database, Web of Science, and Cumulative Index to Nursing and Allied Health Literature (CINAHL). Patients with the diagnosis of ET who were treated with MRgFUS were included in the study. The change in the Clinical Rating Scale for Tremor (CRST) score after treatment was analyzed. The improvement in disability was assessed with the Quality of Life in Essential Tremor Questionnaire (QUEST) score. The pooled data were analyzed by the DerSimonian-Laird random-effects model. Tests for bias and heterogeneity were performed.

RESULTS Nine studies with 160 patients who had ET were included in the meta-analysis. The ventral intermediate nucleus was the target in 8 of the studies. The cerebellothalamic tract was targeted in 1 study. There was 1 randomized controlled trial, 6 studies were retrospective, and 2 were prospective. The mean number of sonications given in various studies ranged from $11 \pm 3.2$ to $22.5 \pm 7.5$ (mean $\pm \mathrm{SD}$ ). The maximum delivered energy ranged from 10,320 \pm 4537 to $14,497 \pm 6695$ Joules. The mean of peak temperature reached ranged from $53^{\circ} \mathrm{C} \pm 2.3^{\circ} \mathrm{C}$ to $62.0^{\circ} \mathrm{C} \pm 2.5^{\circ} \mathrm{C}$. On meta-analysis with the random-effects model, the pooled percentage improvements in the CRST Total, CRST Part A, CRST Part C, and QUEST scores were $62.2 \%, 62.4 \%, 69.1 \%$, and $46.5 \%$, respectively. Dizziness was the most common in-procedure complication, occurring in $43.4 \%$, followed by nausea and vomiting in $26.85 \%$ (pooled percentage). At 3 months, ataxia was the most common complication, occurring in $32.8 \%$, followed by paresthesias in $25.1 \%$ of the patients. At 12 months posttreatment, the ataxia had significantly recovered and paresthesias became the most common persisting complication, at $15.3 \%$.

CONCLUSIONS The MRgFUS therapy for ET significantly improves the CRST scores and improves the quality of life in patients with ET, with an acceptable complication rate. Therapy with MRgFUS is a promising frontier in functional neurosurgery.

https://thejns.org/doi/abs/10.3171/2017.11.FOCUS17628

KEY WORDS MR-guided focused ultrasound; essential tremor; ventral intermediate nucleus; thalamotomy

$\mathrm{H}$ IGH-INTENSITY focused ultrasound is a novel and emerging technique that uses ultrasound waves as carriers of energy. It was used as early as the 1950 s for the treatment of Parkinson disease. After the advent of levodopa therapy, its application was forgotten. ${ }^{12}$ Focused ultrasound came back to modern relevance with its use in prostate cancer in $1994 .{ }^{26}$ The ultrasound waves traverse intervening tissues and generate heat at the point of focus. The use of the phased-array transducer technique allows for ultrasound beam steering and focusing without attenuation. Ultrasound waves interact with biological tissue, producing a variety of effects, like acoustic cavitation, shear stress, and thermal effect. The ultrasound waves cause vibrations of molecules, which in turn gen-

ABBREVIATIONS CRST = Clinical Rating Scale for Tremor; CTT = cerebellothalamic tract; DBS = deep brain stimulation; ET = essential tremor; GKT = Gamma Knife thalamotomy; MRgFUS = MR-guided focused ultrasound; PRISMA = Preferred Reporting Items for Systematic Reviews and Meta-Analyses; QUEST = Quality of Life in Essential Tremor Questionnaire; RCT = randomized controlled trial; Vim = ventral intermediate nucleus.

SUBMITTED October 2, 2017. ACCEPTED November 22, 2017

INCLUDE WHEN CITING DOI: 10.3171/2017.11.FOCUS17628. 
erates frictional heat. Protein denaturation or coagulative necrosis occurs in the cells at a temperature of $56^{\circ} \mathrm{C}$ for 1 second..$^{18}$ Because sound produces an alternating rarefaction, this generates acoustic cavitation. The skull presents a high acoustic impedance to the ultrasound as it absorbs and reflects the waves. Another problem with the bone is that it may cause aberration of the waves. There is heat generation in the skull due to this, and external cooling has to be done in between the sonications. The present study is aimed at understanding the outcomes and complications of this fascinating new technology in the treatment of essential tremor (ET).

Essential tremor is the most common adult movement disorder, occurring at a crude prevalence of $0.08-220$ per thousand persons. ${ }^{25}$ Essential tremor can be viewed more as a syndrome of different clinical features than a single entity. ${ }^{10}$ The presence of ET can cause significant functional and psychological disability, and hence the term "benign" has largely been abandoned in its nomenclature. ${ }^{14}$ The incidence is higher in the white than in the African American population..$^{24}$ Increasing age has been consistently associated with the incidence and prevalence of ET. ${ }^{2}$ The tremor in ET is both kinetic and postural, and may involve other parts of the body, like the head, voice, jaw, tongue, or legs.? The primary therapy for ET is medical treatment. Medical therapy alone is able to reduce tremor in 50\%-60\% of patients. ${ }^{5,6}$ Pharmacological therapy is the first line and mainstay of ET treatment. However, it has been estimated that $25 \%-55 \%$ of patients do not show a clinically satisfactory response to medical therapy alone..$^{11,39}$ Abnormal cerebellothalamic outflow has been hypothesized as the factor that leads to ET. ${ }^{16,23}$ The ventral intermediate nucleus (Vim) of the thalamus is a relay nucleus in the thalamus through which the cerebellothalamic tract (CTT) pathway proceeds, and is the target site for ablation..$^{36}$ The high density of fibers and its distance from the sensory nucleus make the CTT a target for ablation. ${ }^{32}$

\section{Methods}

The aim of the study was to analyze the outcomes of MR-guided focused ultrasound (MRgFUS) therapy in the treatment of ET. The outcome parameters that were analyzed were the Clinical Rating Scale for Tremor (CRST) scores and the scale's subsections. The quality of life and disability improvement was assessed using the Quality of Life in Essential Tremor Questionnaire (QUEST) score. A detailed protocol about the literature search, inclusion and exclusion criteria, selection of cases, and statistical methodology was developed. The guidelines of the Preferred Reporting Items for Systematic Reviews and Meta-Analyses (PRISMA) were followed. Two investigators (N.M. and D.P.) performed the literature search independently. To minimize selection bias, 2 reviewers assessed the articles independently. In case of doubt, a mutual consensus was reached after discussion with the senior author.

\section{Literature Search Strategy}

A computerized Web search of the titles and abstracts from January 1950 to August 2017 in PubMed, Cochrane library database, Web of Science, and Cumulative Index to Nursing and Allied Health Literature (CINAHL) was performed. A combination of key word searches was made to build a search strategy. The non-English articles were also searched. An independent Web search was made with the key words to include any unpublished literature (Fig. 1A). Some of the key words that were used to build the search directory were "focused ultrasound," "essential tremor," "venterointermediate nucleus," "deep brain stimulation," "thalamotomy," and "MR-guided."
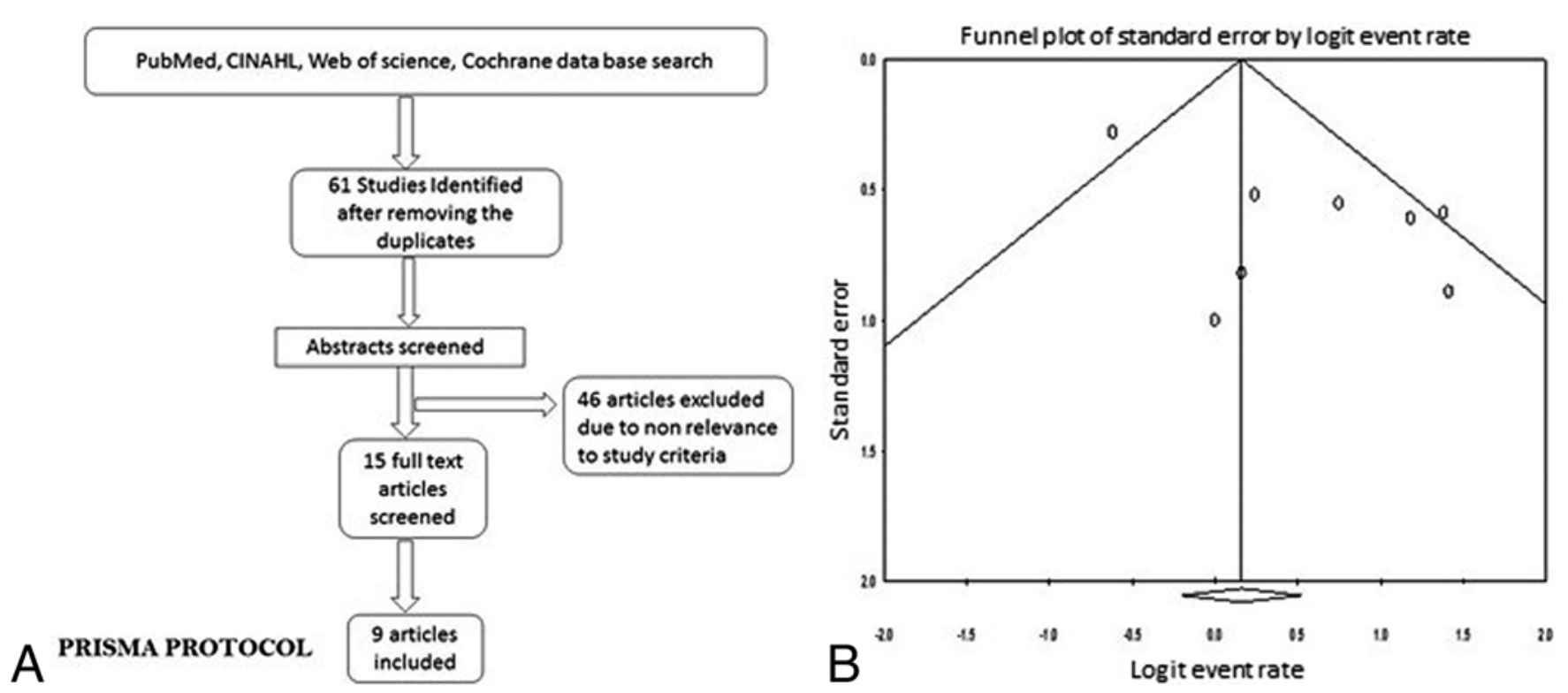

FIG. 1. The PRISMA flowchart and funnel plot. A: The PRISMA flowchart. B: A funnel plot of the studies evaluating CRST Total scores. The plot shows an unequal distribution of studies and the presence of bias. The fail-safe test was performed. The number of missing studies that would bring the $p$ value to $>\alpha$ was found to be 1 . 
TABLE 1. Details of studies included in a meta-analysis of MRgFUS in treatment of ET

\begin{tabular}{|c|c|c|c|c|c|c|c|c|c|}
\hline Authors \& Year & $\begin{array}{l}\text { No. of } \\
\text { Pts }\end{array}$ & $\begin{array}{l}\text { Age in Yrs } \\
\text { (range) }\end{array}$ & $\begin{array}{l}\operatorname{Sex} \\
(M / F)\end{array}$ & $\begin{array}{l}\text { Duration of Sx } \\
\text { in Yrs (range) }\end{array}$ & $\begin{array}{l}\text { Site of } \\
\text { Lesion }\end{array}$ & Type of Study & Sonications & $\begin{array}{l}\text { Max Energy } \\
\text { (Joules) }\end{array}$ & $\begin{array}{c}\text { Peak Temp } \\
\left({ }^{\circ} \mathrm{C}\right)\end{array}$ \\
\hline Zaaroor et al., 2018 & 18 & $68.9 \pm 8.3$ & NS & $12.1 \pm 8.9$ & Vim & Retro & $21.0 \pm 6.9$ & $12,500 \pm 4,274$ & $56.5 \pm 2.2$ \\
\hline SchregImann et al., 2017 & 6 & $70.7 \pm 8.5$ & NS & $24.5 \pm 22.5$ & CTT & Pros & $11 \pm 3.2$ & $12,008 \pm 4,441$ & $62.0 \pm 2.5$ \\
\hline Elias et al., 2013 & 15 & $66.6 \pm 8$ & $11 / 4$ & $32 \pm 21.3$ & Vim & $\begin{array}{l}\text { Uncontrolled, pros } \\
\text { study }\end{array}$ & $17.9 \pm 4.6$ & $10,320 \pm 4,537$ & $58.5 \pm 2.5$ \\
\hline Lipsman et al., 2013 & 4 & $70.8(58-77)$ & $4 / 0$ & $17.8 \pm 8.18$ & Vim & Pros, uncontrolled & $22.5 \pm 7.59$ & NS & $59 \pm 2.87$ \\
\hline Huss et al., 2015 & 15 & $67.2(28-82)$ & $10 / 5$ & NS & Vim & Retro & NS & NS & NS \\
\hline Kim et al., 2017 & 23 & $64.7(47-77)$ & $20 / 3$ & $20.5(5-54)$ & Vim & Retro & NS & NS & 55.62 \\
\hline Chang et al., 2015 & 8 & $65.72(53-78)$ & $9 / 2$ & $30.6 \pm 16.12$ & Vim & Retro & NS & NS & $53 \pm 3.3$ \\
\hline Wintermark et al., 2014 & 15 & $67 \pm 8$ & $10 / 5$ & NS & Vim & Retro & NS & NS & NS \\
\hline Elias et al., 2016 & 56 & $71 \pm 8.3$ & $37 / 19$ & $16.8 \pm 12.3$ & Vim & RCT & $18.5 \pm 5.2$ & $14,497 \pm 6,695$ & $55.6 \pm 2.3$ \\
\hline
\end{tabular}

NS = not specified; pros = prospective; pts = patients; retro = retrospective; $\mathrm{Sx}=$ symptoms; temp = temperature.

Unless otherwise stated, values are presented as the mean \pm SD.

\section{Bias Assessment}

Two investigators independently reviewed all the articles to eliminate the selection bias. A meta-analysis of proportions was performed. The present study involves mainly observational studies and 1 randomized controlled trial (RCT). Funnel plots were charted. The Q statistic and $\mathrm{I}^{2}$ were calculated to assess heterogeneity. The $\mathrm{I}^{2}$ value was high in most analyses, indicating increased heterogeneity.

\section{Inclusion and Exclusion Criteria}

The diagnosis of ET was based on the consensus statement of the Movement Disorder Society. The inclusion criteria consist of the presence of bilateral postural tremor with or without kinetic component tremor, involving hands and forearms, that is visible and persistent-lasting for more than 5 years. The diagnosed cases of ET that were treated with MRgFUS were included in the study. All the cases that were treated with MRgFUS were refractory to medical therapy. Medication-refractory tremor was defined as persistent disabling tremor despite at least 2 trials of a full-dose therapeutic medication, 1 of which had to include propranolol or primidone. The cases of ET that were associated with Parkinson disease and those treated with deep brain stimulation (DBS) or stereotactic ablation were excluded. For the purpose of statistical analysis, only studies that assessed the tremor outcome by using the CRST were included. The diagnosis of ET was based on the Movement Disorder Society's consensus statement. The cases in which the patient had suffered a head injury prior to 3 months of onset of tremor, cases with a psychogenic origin, those with abnormal neurological signs, druginduced or drug withdrawal-related cases, or those with a known cause of physiological tremor were excluded from the study. ${ }^{5}$

\section{Tremor Scoring System}

The CRST is a scoring system used to evaluate the severity of the ET. The CRST has 3 parts. ${ }^{33}$ Part A evaluates the tremor, Part B evaluates task performance, and Part $\mathrm{C}$ evaluates the disability due to the tremor. The 3 parts contribute to a total of 160 points; higher scores reflect a more severe tremor. Part A has a score range from 0 to 32 summarizing 8 items, and is the primary clinical end point of interest. The baseline and posttreatment CRST scores were noted. The QUEST scoring was also used to evaluate the quality of life improvement following the treatment. The QUEST is scored from $0 \%$ to $100 \%$; higher scores reflect a greater perceived disability.

\section{Statistical Analysis}

Statistical analysis was done using Comprehensive Meta Analysis software (version 3.3.070). Due to the inherent heterogeneity of observational studies, the randomeffects model was used for the meta-analysis. The metaanalysis of proportions was performed, as was the test for heterogeneity. The $\mathrm{I}^{2}$ value and Q statistic were evaluated. The DerSimonian-Laird model was used to calculate the pooled effect. Forest plots were charted for the tremor score subsections. Bias assessment was done using the funnel plots (Fig. 1B).

\section{Results}

Nine studies with 160 patients who matched the inclusion and exclusion criterion were considered for the present study (Table 1). The mean age was highest in the study by Schreglmann et al. ${ }^{32}$ at $70.7 \pm 8.5$ years, and lowest in that of Kim et al. ${ }^{19}$ at 64.7 years. The means of the duration of tremor in patients in various studies ranged from 12.1 years to 32 years. The Vim was the target in 8 studies, whereas the CTT was targeted in 1 study. ${ }^{32}$ There was 1 RCT, 6 studies were retrospective, and 2 were prospective. There were 2 studies from Elias et al. ${ }^{89}$ The first was a pilot study, including 15 patients. ${ }^{8}$ The second was an RCT that included 56 patients. ${ }^{9}$ The mean number of sonications given in various studies ranged from $11 \pm 3.2^{32}$ to $22.5 \pm 7.6^{22}$ (mean $\pm \mathrm{SD}$ ). The maximum delivered energy ranged from $10,320 \pm 4537^{8}$ to $14,497 \pm 6695$ Joules. ${ }^{9}$ The mean of peak temperature reached ranged from $53^{\circ} \mathrm{C} \pm$ $2.3^{\circ} \mathrm{C}$ to $62.0^{\circ} \mathrm{C} \pm 2.5^{\circ} \mathrm{C}$.

The tremor was evaluated using the CRST..$^{33}$ The base- 


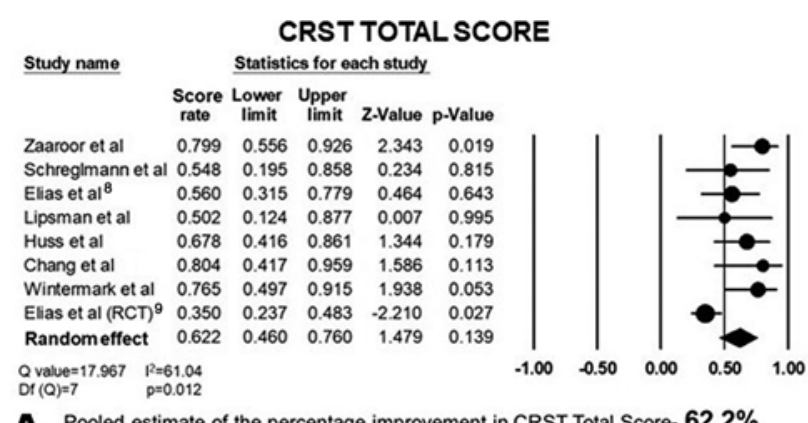

A Pooled estimate of the percentage improvement in CRST Total Score- $62.2 \%$

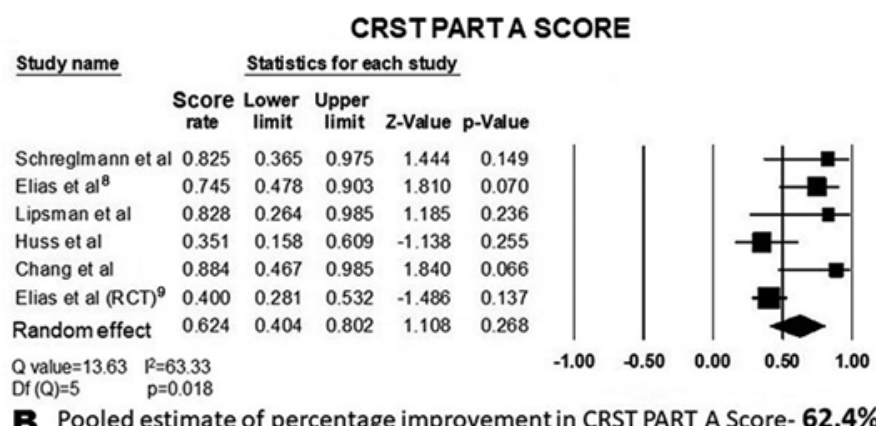

3 Pooled estimate of percentage improvement in CRST PART A Score- $62.4 \%$

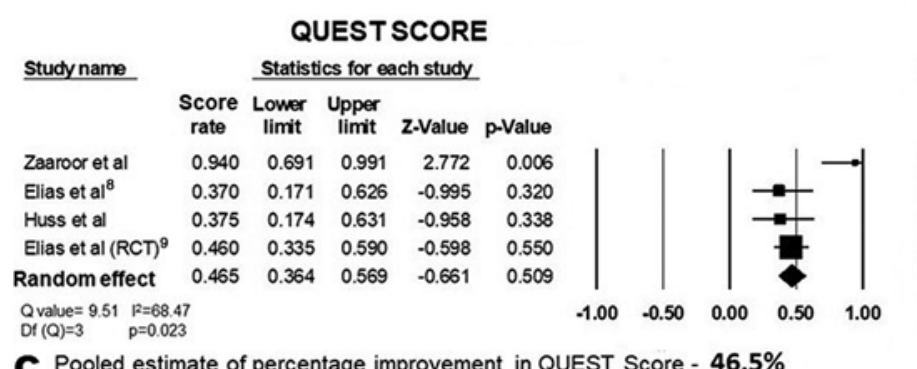

C Pooled estimate of percentage improvement in QUEST Score - $46.5 \%$

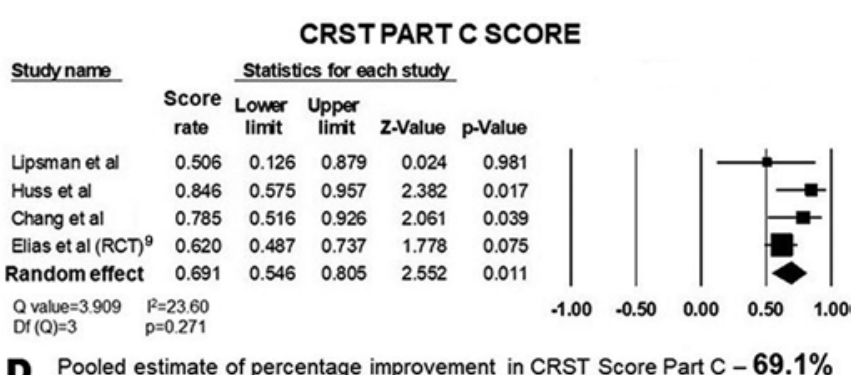

CRST PART C SCORE

D Pooled estimate of percentage improvement in CRST Score Part C - $69.1 \%$

FIG. 2. Pooled estimate of CRST Total, Part A, QUEST, and Part C scores. A: Pooled estimate of percentage improvement in CRST Total score. B: Pooled estimate of percentage improvement in CRST Part A score. C: Pooled estimate of percentage improvement in QUEST score. D: Pooled estimate of percentage improvement in CRST Part C score.

line scores and postprocedure improvement of the scores were recorded. The mean percentage change in the score was then calculated. The results were subjected to metaanalysis and the pooled percentage change in the scores was obtained. The complications were divided into 3 groups. Complications occurring during the procedure were analyzed separately as a group. The CRST Total and CRST Part A scores were subdivided into 2 groups. Those complications that occurred at 3 or 6 months were grouped together to evaluate the short-term outcomes, and those that occurred at 12 months were analyzed separately to evaluate the long-term outcomes, whereas the CRST Part $\mathrm{C}$ score that assessed the disability was studied at 6 or 12 months only. The CRST Part B score was included in the CRST Total score and was not calculated separately. The pooled percentage of complications at different time periods was then analyzed.

\section{The CRST Total Score}

The CRST Total score at baseline was compared with that of postprocedure scores. The CRST Total scores showed good improvement in all studies. The latest CRST score was used to compare the results. The study by Elias et al. ${ }^{9}$ showed the lowest improvement in the scores at $35 \%$. The highest improvement in the tremor score was in the study by Chang et al., at $80.43 \%{ }^{4}$ The study by Kim et al. ${ }^{19}$ did not report the actual CRST Total scores, but reported the percentage of patients who had improvement in the ET. This study was not included in the statistical analysis for CRST Total scores. On meta-analysis with the random-effects model, the pooled improvement in the CRST Total scores was $62.2 \%$. The improvement in score reflects the reduction in the severity and associated disability due to the tremor (Fig. 2A and Table 2).

\section{The CRST Part A Score}

The CRST Part A score evaluates the hand tremor severity and is the principal end point of interest in treatment of ET. Higher scores reflect more severe tremor. All studies showed good improvement in the hand tremor severity (Table 2). The percentage improvement in the score ranged from $35.07 \%{ }^{15}$ to $88.42 \%$. $^{4}$ The pooled percentage improvement of the CRST Part A study after the metaanalysis is $62.4 \%$ (Fig. 2B).

\section{The CRST Part C and QUEST Scores}

The CRST Part C score takes into consideration the disability due to the ET. Higher scores reflect greater disability. The percentage improvement indicates the reduction in disability. The pooled analysis showed a $69.1 \%$ reduction in the CRST Part C scores due to the treatment. The QUEST score also evaluates the improvement in disability due to ET after the treatment. The pooled improvement in QUEST scores after the analysis was 46.5\% (Fig. 2C and D).

\section{In-Procedure Complications}

In-procedure complications are those that occur during the sonications and that resolve following completion of the treatment. The common complications that occurred in the studies included headache, dizzy feeling, nausea and vomiting, sensation of warmth in the scalp or flushing, and paresthesias (Table 3). Dizziness was the most common in-procedure complication that occurred. The pooled percentage of in-procedure dizziness occurring in patients was found to be $43.4 \%$. Nausea and vomiting is the next most frequent in-procedure complication, occurring at $26.8 \%$ (pooled estimate). The percentage of occurrence of in-procedure headache, sensation of warmth or 
TABLE 2. Baseline CRST Total, Part A, Part C, and QUEST scores, and percentage improvement at 3, 6, or 12 months

\begin{tabular}{|c|c|c|c|c|}
\hline Authors \& Year & $\begin{array}{l}\text { CRST Total Score at } \\
\text { Baseline (mean } \pm \text { SD) }\end{array}$ & $\begin{array}{l}\text { CRST Total Score at } 3 \text { or } \\
6 \text { Mos (mean } \pm \text { SD) }\end{array}$ & $\begin{array}{l}\text { CRST Total Score at } \\
12 \text { Mos (mean } \pm \text { SD) }\end{array}$ & $\begin{array}{l}\text { CRST Total Score, } \\
\% \text { Improvement }\end{array}$ \\
\hline \multicolumn{5}{|l|}{ CRST Total } \\
\hline Zaaroor et al., 2018 & $40.7 \pm 11.6$ & $8.2 \pm 5.0$ (6 mos $)$ & NS & 79.85 \\
\hline SchregImann et al., 2017 & $43.8 \pm 9.8$ & $19.8 \pm 6.8$ (6 mos) & NS & 54.79 \\
\hline Elias et al., 2013 & $54.9 \pm 14.4$ & NS & $24.3 \pm 14.8$ & 56 \\
\hline Lipsman et al., 2013 & $70.75 \pm 19.6$ & $35.25 \pm 10.9$ (3 mos) & NS & 50.17 \\
\hline Huss et al., 2015 & 54.9 & NS & 17.7 & 67.75 \\
\hline Kim et al., 2017 & NS & NS & NS & $78.3 \%$ improved at $12 \mathrm{mos}$ \\
\hline Chang et al., 2015 & $46.72 \pm 10.51$ & $6.25 \pm 7.16(6 \mathrm{mos})$ & NS & 80.43 \\
\hline Wintermark et al., 2014 & $19.8 \pm 5^{*}$ & $4.6 \pm 3$ (3 mos $)$ & NS & 76.5 \\
\hline Elias et al., 2016 & $50.1 \pm 14.0$ & $29.6 \pm 13$ (3 mos) & $32.4 \pm 14.5$ & 35 \\
\hline CRST Part A & $\begin{array}{l}\text { CRST Part A score at } \\
\text { baseline (mean } \pm \text { SD) }\end{array}$ & $\begin{array}{l}\text { CRST Part A score at } 3 \text { or } \\
6 \text { mos (mean } \pm \text { SD) }\end{array}$ & $\begin{array}{l}\text { CRST Part A score at } \\
12 \text { mos (mean } \pm \text { SD) }\end{array}$ & $\begin{array}{l}\text { CRST Part A score, } \\
\% \text { improvement }\end{array}$ \\
\hline Schreglmann et al., 2017 & $14.3 \pm 4.9$ & $2.5 \pm 2.1(6 \mathrm{mos})$ & NS & 82.51 \\
\hline Elias et al., 2013 & $20.4 \pm 5.2$ & $4.3 \pm 3.5(3 \mathrm{mos})$ & $5.2 \pm 4.8$ & 74.50 \\
\hline Lipsman et al., 2013 & $7.25 \pm 2.2$ & $1.25 \pm 0.95$ (3 mos) & NS & 82.75 \\
\hline Huss et al., 2015 & 13.4 & NS & 8.7 & 35.07 \\
\hline Chang et al., 2015 & $12.09 \pm 2.9$ & $1.4 \pm 1.59(6 \mathrm{mos})$ & NS & 88.42 \\
\hline Elias et al., 2016 & $18.1 \pm 4.8$ & $9.6 \pm 5.1$ (3 mos) & $10.9 \pm 4.5$ & 40 \\
\hline QUEST \& CRST Part C & $\begin{array}{l}\text { QUEST score, } \\
\% \text { improvement }\end{array}$ & $\begin{array}{l}\text { CRST Part C score at } \\
\text { baseline (mean } \pm \text { SD) }\end{array}$ & $\begin{array}{l}\text { CRST Part C score at } 6 \text { or } \\
12 \text { mos (mean } \pm \text { SD) }\end{array}$ & $\begin{array}{l}\text { CRST Part C score, } \\
\% \text { improvement }\end{array}$ \\
\hline Zaaroor et al., 2018 & $94 \%$ & NS & NS & NS \\
\hline Elias et al., 2013 & $37 \%$ & NS & NS & NS \\
\hline Lipsman et al., 2013 & NS & $20.75 \pm 4.5$ & $10.25 \pm 3.3$ (12 mos) & 50.60 \\
\hline Huss et al., 2015 & $37.5 \%$ & 18.2 & 2.8 (12 mos) & 84.61 \\
\hline Chang et al., 2015 & NS & $12.81 \pm 3.62$ & $2.75 \pm 3.49$ (6 mos) & 78.51 \\
\hline Elias et al., 2016 & $46 \%$ & $16.5 \pm 4.6$ & $6.3 \pm 5.6$ (12 mos $)$ & 62 \\
\hline
\end{tabular}

Unless otherwise stated, values are presented as the mean \pm SD.

* The score denotes Part A and Part B subsections only.

flushing, and paresthesias was found to be $24.3 \%, 19.8 \%$, and $13.1 \%$, respectively. The frame-related complications were also included in this group. Ten instances of pin site complications were noted. There were 4 cases of pin site burns, 9 cases of occipital numbness, and 6 cases of pin site hematoma. Chang et al. ${ }^{4}$ noted 3 cases of failure to reach the target temperature despite increasing the energy and number of sonications. One patient in the study by Lipsman et al. ${ }^{22}$ developed deep venous thrombosis secondary to the length of the procedure (Fig. 3A and B).

\section{Complications at 3 Months After Treatment}

Ataxia, which includes both objective gait instability and subjective feeling of unsteadiness, was the most com-

TABLE 3. In-procedure complications

\begin{tabular}{|c|c|c|c|c|c|c|c|}
\hline Authors \& Year & Headache & $\begin{array}{l}\text { Dizzy } \\
\text { Feeling }\end{array}$ & $\begin{array}{c}\text { Nausea } \\
\& \\
\text { Vomiting }\end{array}$ & $\begin{array}{l}\text { Sensation of } \\
\text { Heat, Warmth, } \\
\text { or Flushing }\end{array}$ & $\begin{array}{l}\text { Scalp } \\
\text { Tingling }\end{array}$ & Paresthesias & Frame Related \& Others \\
\hline Zaaroor et al., 2018 & 0 & 14 & 5 & 0 & 3 & 2 & Scalp numbness (5), subcutaneous hematoma (3) \\
\hline Schreglmann et al., 2017 & 0 & 4 & 0 & 0 & 0 & 0 & 0 \\
\hline Elias et al., 2013 & 9 & 5 & 8 & 4 & 0 & 0 & 0 \\
\hline Lipsman et al., 2013 & 0 & 0 & 0 & 0 & 0 & 2 & 0 \\
\hline Huss et al., 2015 & 9 & 11 & 8 & 4 & 0 & 0 & MRI pin site burn (2) \\
\hline Kim et al., 2017 & NS & NS & NS & NS & NS & NS & NS \\
\hline Chang et al., 2015 & 0 & 5 & 0 & 0 & 0 & 0 & Sonication failures (3) \\
\hline Wintermark et al., 2014 & 0 & 0 & 0 & 0 & 0 & 0 & Pin site burn (2), occipital numbness (4) \\
\hline Elias et al., 2016 & 2 & 12 & 13 & 17 & 0 & 4 & Pin site edema (3), back pain (5), anxiety (3) \\
\hline
\end{tabular}




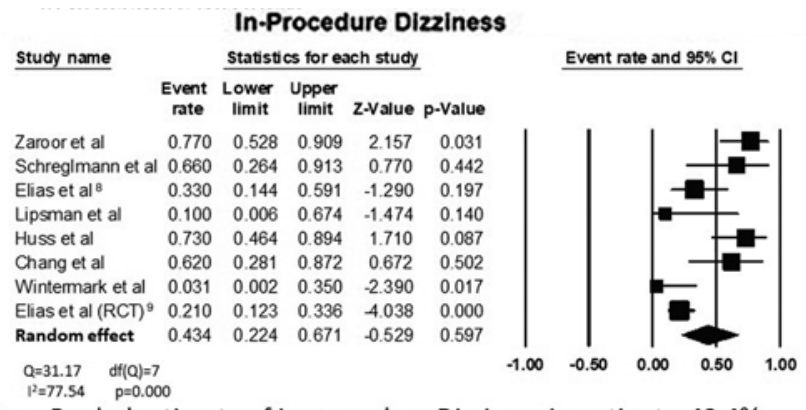

A Pooled estimate of in-procedure Dizziness in patients- $43.4 \%$

Paresthesias occurring between 0 to 3 months

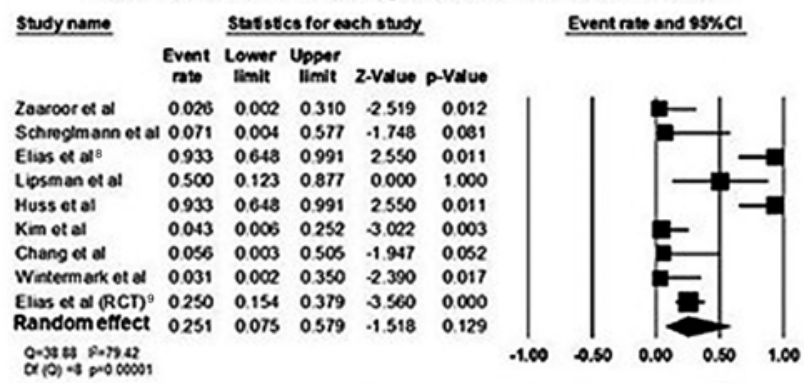

c

Pooled estimate of paresthesias occurring in patients at 3 months. $25.1 \%$

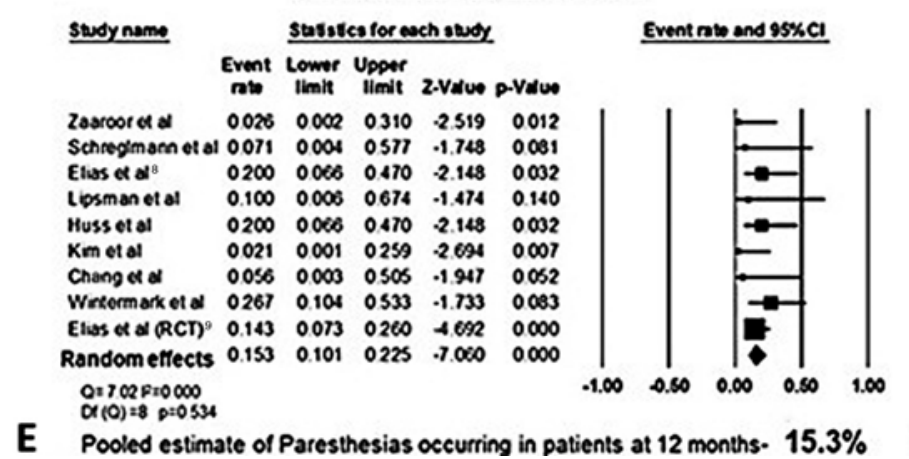

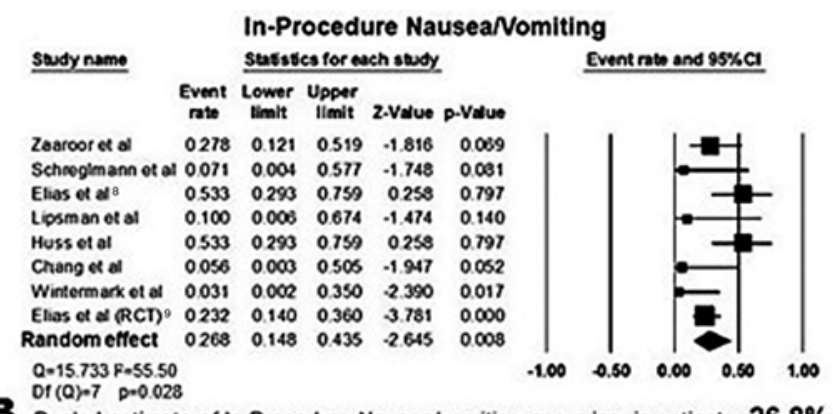

Ataxia occurring between 0 to 3 months

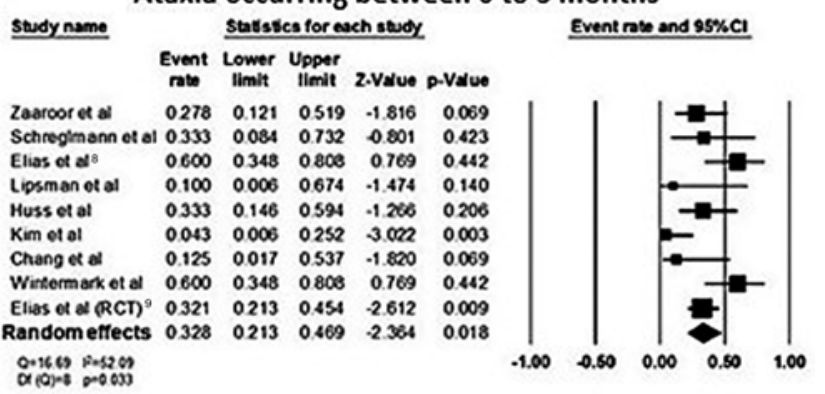

D Pooled estimate of Ataxia occurring in patients at 3 months. $32.8 \%$

FIG. 3. Pooled estimate of in-procedure complications, and complications at 3 and 12 months postprocedure. A: Pooled estimate of in-procedure dizziness. B: Pooled estimate of in-procedure nausea and vomiting. C: Pooled estimate of paresthesias occurring in patients at 3 months postprocedure. D: Pooled estimate of ataxia occurring in patients at 3 months postprocedure. E: Pooled estimate of paresthesias occurring in patients at 12 months postprocedure. F: Pooled estimate of ataxia occurring in patients at 12 months postprocedure.

mon complaint at 3 months (Table 4). The pooled estimate of ataxia occurring at 3 months was $32.8 \%$. In other words, one-third of the patients had some form of gait instability persisting at 3 months posttreatment. Paresthesias were the next most common complication persisting at 3 months. The meta-analysis showed that $25.1 \%$ of patients had this complication at 3 months. Other complications, like dysarthria, limb weakness, dysmetria, tinnitus, fatigue, and dysgeusia, occurred at the rate of $4.1 \%, 5.6 \%, 8.4 \%, 5.35 \%$, $5.35 \%$, and $4.4 \%$, respectively (pooled percentage; Fig. 3C and D).

\section{Complications at 12 Months After Treatment}

At 12 months, paresthesias became the most common persisting complaint. Approximately $15.3 \%$ of the patients continued to have paresthesias at 12 months posttreatment. Paresthesias involved the lips and finger areas. Ataxia, which was the most common complaint at 3 months, had completely resolved in a majority of patients; it was present in $10.5 \%$ of the patients at 12 months. One patient had persisting facial paresis at 12 months. ${ }^{19}$ Thus, there was a significant reduction in the number of persisting complications at the end of 12 months after treatment with MRgFUS for ET (Fig. 3E and F).

\section{Discussion}

Two parameters were the focus of this study. The first was to analyze the improvement in the CRST score following the treatment, and the second was to categorize the complications temporally and estimate their overall inci- 
TABLE 4. Complications occurring between 0 and 3 months (resolved and persisting)

\begin{tabular}{lccccccccc}
\hline \multicolumn{1}{c}{ Authors \& Year } & $\begin{array}{c}\text { Paresthesias or } \\
\text { Dysesthesias }\end{array}$ & Dysarthria & Dysphagia & $\begin{array}{c}\text { Gait Instability, Ataxia, } \\
\text { or Unsteady Feeling }\end{array}$ & $\begin{array}{c}\text { Limb } \\
\text { Weakness }\end{array}$ & Dysmetria & Tinnitus & Fatigue \\
Dysgeusia
\end{tabular}

dence. All the studies demonstrated a good improvement in the total tremor scores and the subsections of the CRST scores. $., 9,15,19,22,32,36,38$ Our analysis showed a significant improvement of CRST Total scores, CRST Part A scores, CRST Part C scores, and QUEST scores by $62.2 \%, 62.4 \%$, $69.1 \%$, and $46.5 \%$, respectively. The study by Elias et al., ${ }^{9}$ which included 56 patients, was the only RCT. This study showed a significant 35\% improvement in the CRST Total score at 12 months. Importantly, the improvements in tremor scores were maintained at 12 months. Gait disturbance and paresthesias occurred in $36 \%$ and $38 \%$ of the patients at 3 months and in $9 \%$ and $14 \%$ at the end of 12 months, respectively.

In the study by Chang et al., ${ }^{4}$ patients in 3 cases failed to achieve the target temperature despite increasing the intensity and number of sonications. The authors found a linear correlation between skull volume and the maximum temperature reached at the target site. Schreglmann et al. ${ }^{32}$ was the only study that targeted the CTT. No paresthesias were found in their patients with complications. This can be explained by the distance of the CTT from the thalamic sensory nucleus. The CTT is a possible target for MRgFUS in the future and may lead to reduction of paresthesias. Huss et al. ${ }^{15}$ compared the outcomes in patients treated with bilateral DBS, unilateral DBS, and unilateral MRgFUS. Bilateral DBS was done in 57 patients, unilateral DBS was done in 13 patients, and unilateral MRgFUS in 15 patients. As compared with unilateral DBS, this study found that the MRgFUS group had similar tremor suppression rates. The tremor suppression scores were significantly better in the bilateral DBS group than in the unilateral DBS or MRgFUS group. However, this was also associated with a corresponding increase in the complication rate in the bilateral DBS group. The quality of life improvement, however, was not found to be statistically different between the groups, which reflects the effect of controlling the dominant hand tremor.

Almost half the patients complained of dizziness during the procedure. The high magnetic field exposure has been linked to the pathogenesis of dizziness and vertigo. Magnetic resonance-induced vertigo is a known phenomenon that occurs in patients exposed to a magnetic field of more than 2 Tesla and a prolonged duration of exposure. ${ }^{4}$ This may be a cause of discomfort for the patient considering the prolonged time required for the treatment. The prolonged treatment time is mainly due to the requirement for cooling between the sonications. One-quarter of the patients developed nausea and vomiting during the procedure. The occurrence of paresthesias can be explained by the proximity of the ventroposterolateral nucleus, which relays the sensory fibers. Another complication noted in the present study was pin site burn due to MRI-induced heating of the pins.

After its FDA approval in 1997, DBS has become the current standard surgical treatment for medication-refractory ET. It was Benabid and colleagues in 1987 who showed the beneficial effects of high-frequency stimulation of the Vim in the thalamus in reducing tremor. ${ }^{1}$ The Vim is the target of DBS in the treatment of ET. Several studies have shown that subthalamic regions below the Vim, like the radiation prelemniscalis and caudal zona incerta, can also improve the symptoms of ET when selected as targets. ${ }^{27,31}$ Loss of tremor control can occur gradually over the years following DBS. This has been suggested to be due to tolerance, and the stimulation parameters can be adjusted. ${ }^{3}$ The total tremor score improvements in various studies range from $34 \%$ to $83 \% .^{3,30}$ Kenney et al. ${ }^{18}$ studied 319 patients treated with DBS, of which 112 patients had ET. The in-procedure adverse events included vasovagal response in $2.5 \%$, severe cough in $0.9 \%$, transient ischemic attack in $0.3 \%$, arrhythmia in $0.3 \%$, and confusion in $0.3 \%$ of the patients. Perioperative complications included headaches in $15 \%$, confusion in 5\%, hallucinations in $2.8 \%$, seizures in $1.2 \%$, intracerebral hemorrhage in $0.6 \%$, and intraventricular hemorrhage and large subdural hemorrhage in $0.3 \%$ of the patients. Persistent long-term complications were dysarthria in $4 \%$, gait disturbance in $3.8 \%$, cognitive dysfunction in $4 \%$, and infection in $4.4 \%$. To add to the list, hardware problems like lead fractures and migrations also occurred.

A revision rate of $7.8 \%$ was noted in this series. ${ }^{18}$ Other series have shown that hardware complications like lead fracture, infection, skin erosion, and cable connection failure occur in up to one-quarter of patients. ${ }^{40}$ Okun et al. ${ }^{29}$ found suboptimally placed electrodes in $46 \%$, inadequate follow-up programming in $17 \%$, and suboptimal DBS parameters in $37 \%$ of the cases. Voges et al. analyzed the complication rate after DBS in 1183 patients and found a 30 -day mortality rate of $0.4 \%$ and permanent surgical morbidity at $1 \% .{ }^{35}$ However, DBS is not an ablative procedure. Some of the complications can be reduced or eliminated 
TABLE 5. Summary of critical appraisal of included studies using the Newcastle-Ottawa Scale for assessing the quality of observational studies

\begin{tabular}{lccc}
\hline \multicolumn{1}{c}{ Study } & Selection & Comparability & Exposure \\
\hline Zaaroor et al., 2018 & ${ }^{* *}$ & $*$ & $* *$ \\
\hline Schreglmann et al., 2017 & ${ }^{* *}$ & & ${ }^{*}$ \\
\hline Elias et al., 2013 & ${ }^{* *}$ & & ${ }^{*}$ \\
\hline Lipsman et al., 2013 & ${ }^{* *}$ & & \\
\hline Huss et al., 2015 & $* * *$ & $* *$ & $*$ \\
\hline Kim et al., 2017 & $* * *$ & $* *$ & $*$ \\
\hline Chang et al., 2015 & $* *$ & & \\
\hline Wintermark et al., 2014 & $* *$ & & \\
\hline Elias et al., 2016 & $* * *$ & & \\
\hline
\end{tabular}

Each of the 3 categories has further subcategories of assessment for which an asterisk is given. Studies with the maximum number of asterisks have a higher quality than those with fewer asterisks. Empty cells indicate that no asterisks could be scored for that category.

by adjusting the stimulation parameters. This reversibility is not possible in ablative procedures like thalamotomy and MRgFUS. ${ }^{34}$ It should also be noted that although DBS is reversible and nonablative, it is still invasive-and complications like hemorrhage, seizures, suboptimal electrode placement, and infection can occur.

Gamma Knife thalamotomy (GKT) is a noninvasive procedure that lacks the real-time feedback of tremor reduction and electrophysiological confirmation. The radiation takes time (months to years) to show the clinical response..$^{21}$ The usual dose used is $130-140$ Gy, delivered by a single 4-mm collimator. The GKT procedure is done usually when the patients are unable to receive DBS, such as those on anticoagulation in whom DBS is risky. Advanced age, medical comorbidities, and patient preferences are other factors that may influence the choice of GKT. ${ }^{20}$ Accuracy of targeting is not as good as the intraoperative electrophysiological monitoring done in DBS. ${ }^{13}$ The size of the lesion produced by GKT may vary due to unpredictable tissue response to radiation. ${ }^{28}$ Kondziolka et al., in a study of 31 patients with ET who were treated with GKT, showed a $69 \%$ improvement in both action tremor and writing scores. ${ }^{20}$ There was a $12 \%$ failure rate to achieve tremor control in their series. Young et al. ${ }^{37}$ showed an $87.5 \%$ rate of clinical improvement and a $12.5 \%$ failure rate. Jankovic et al. ${ }^{17}$ reported a $58 \%$ temporary complication rate following stereotactic thalamotomy and a $23 \%$ permanent complication rate. Complications like hemiparesis, altered mental status, thalamic hemorrhage, and homonymous hemianopia have been reported. ${ }^{37}$ Radiation necrosis and collateral trajectory tissue damage are a concern. Because of these considerations, GKT is not recommended as a first line of treatment for ET. ${ }^{6}$

\section{Justification for our Analysis}

The MRgFUS technique is relatively new. The outcomes and complications are reported in a small number of studies, and the number of patients in each study is small. This report has been an effort to bring together the studies that have used MRgFUS for the treatment of
ET and to understand its overall impact and the associated complications. A meta-analysis generates a broader perspective by combining the results of all the studies, and summarizes the outcomes and complications. There is a paucity of class 1 studies in this fascinating new frontier. An important goal of this study was to summarize the various complications and their incidences temporally.

\section{Limitations of the Study}

There are a number of limitations of the present study. Most of the included studies were retrospective case series; only 1 RCT was included. Thus, the possibility of bias is high (Table 5). The follow-up period is small. Longer follow-up is required to assess the long-term tremor suppression and complications due to the treatment. The number of patients is small; larger trials with randomization are required. Randomized trials comparing DBS to MRgFUS are the need of the hour.

\section{Conclusions}

The MRgFUS therapy for ET significantly improves the CRST scores and improves the quality of life of patients with ET, with an acceptable rate of complications. The MRgFUS therapy is a promising frontier in functional neurosurgery.

\section{Acknowledgments}

We thank Julia M. Esparza, MLS, AHIP, an associate professor in the Department of Medical Library Science/Health Sciences Library, LSU Health, Shreveport, LA, for assisting in the search strategy. We also thank Ms. Gloria Caldito, an associate professor in the Department of Statistics and Research, LSU, for assistance with the statistical analysis.

\section{References}

1. Benabid AL, Pollak P, Louveau A, Henry S, de Rougemont J: Combined (thalamotomy and stimulation) stereotactic surgery of the VIM thalamic nucleus for bilateral Parkinson disease. Appl Neurophysiol 50:344-346, 1987

2. Benito-León J, Bermejo-Pareja F, Morales JM, Vega S, Molina JA: Prevalence of essential tremor in three elderly populations of central Spain. Mov Disord 18:389-394, 2003

3. Bryant JA, De Salles A, Cabatan C, Frysinger R, Behnke E, Bronstein J: The impact of thalamic stimulation on activities of daily living for essential tremor. Surg Neurol 59:479-485, 2003

4. Chang WS, Jung HH, Kweon EJ, Zadicario E, Rachmilevitch I, Chang JW: Unilateral magnetic resonance guided focused ultrasound thalamotomy for essential tremor: practices and clinicoradiological outcomes. J Neurol Neurosurg Psychiatry 86:257-264, 2015

5. Deuschl G, Bain P, Brin M: Consensus statement of the Movement Disorder Society on Tremor. Mov Disord 13 (Suppl 3):2-23, 1998

6. Deuschl G, Raethjen J, Hellriegel H, Elble R: Treatment of patients with essential tremor. Lancet Neurol 10:148-161, 2011

7. Elble RJ: Report from a U.S. conference on essential tremor. Mov Disord 21:2052-2061, 2006

8. Elias WJ, Huss D, Voss T, Loomba J, Khaled M, Zadicario E, et al: A pilot study of focused ultrasound thalamotomy for essential tremor. N Engl J Med 369:640-648, 2013

9. Elias WJ, Lipsman N, Ondo WG, Ghanouni P, Kim YG, Lee 
W, et al: A randomized trial of focused ultrasound thalamotomy for essential tremor. N Engl J Med 375:730-739, 2016

10. Espay AJ, Lang AE, Erro R, Merola A, Fasano A, Berardelli A, et al: Essential pitfalls in "essential" tremor. Mov Disord 32:325-331, 2017

11. Flora ED, Perera CL, Cameron AL, Maddern GJ: Deep brain stimulation for essential tremor: a systematic review. Mov Disord 25:1550-1559, 2010

12. Fry WJ, Barnard JW, Fry FJ, Brennan JF: Ultrasonically produced localized selective lesions in the central nervous system. Am J Phys Med 34:413-423, 1955

13. Gross RE, Krack P, Rodriguez-Oroz MC, Rezai AR, Benabid AL: Electrophysiological mapping for the implantation of deep brain stimulators for Parkinson's disease and tremor. Mov Disord 21 (Suppl 14):S259-S283, 2006

14. Hedera P: Emerging strategies in the management of essential tremor. Ther Adv Neurol Disorder 10:137-148, 2017

15. Huss DS, Dallapiazza RF, Shah BB, Harrison MB, Diamond J, Elias WJ: Functional assessment and quality of life in essential tremor with bilateral or unilateral DBS and focused ultrasound thalamotomy. Mov Disord 30:1937-1943, 2015

16. Ilinsky IA, Kultas-Ilinsky K: Motor thalamic circuits in primates with emphasis on the area targeted in treatment of movement disorders. Mov Disord 17 (Suppl 3):S9-S14, 2002

17. Jankovic J, Cardoso F, Grossman RG, Hamilton WJ: Outcome after stereotactic thalamotomy for parkinsonian, essential, and other types of tremor. Neurosurgery 37:680-687, 1995

18. Kenney C, Simpson R, Hunter C, Ondo W, Almaguer M, Davidson A, et al: Short-term and long-term safety of deep brain stimulation in the treatment of movement disorders. $\mathbf{J}$ Neurosurg 106:621-625, 2007

19. Kim M, Jung NY, Park CK, Chang WS, Jung HH, Chang JW: Comparative evaluation of magnetic resonance-guided focused ultrasound surgery for essential tremor. Stereotact Funct Neurosurg 95:279-286, 2017

20. Kondziolka D, Ong JG, Lee JY, Moore RY, Flickinger JC, Lunsford LD: Gamma Knife thalamotomy for essential tremor. J Neurosurg 108:111-117, 2008

21. Lim SY, Hodaie M, Fallis M, Poon YY, Mazzella F, Moro E: Gamma knife thalamotomy for disabling tremor: a blinded evaluation. Arch Neurol 67:584-588, 2010

22. Lipsman N, Schwartz ML, Huang Y, Lee L, Sankar T, Chapman M, et al: MR-guided focused ultrasound thalamotomy for essential tremor: a proof-of-concept study. Lancet Neurol 12:462-468, 2013

23. Lorenz D, Deuschl G: Update on pathogenesis and treatment of essential tremor. Curr Opin Neurol 20:447-452, 2007

24. Louis ED, Marder K, Cote L, Pullman S, Ford B, Wilder D, et al: Differences in the prevalence of essential tremor among elderly African Americans, whites, and Hispanics in northern Manhattan, NY. Arch Neurol 52:1201-1205, 1995

25. Louis ED, Ottman R, Hauser WA: How common is the most common adult movement disorder? Estimates of the prevalence of essential tremor throughout the world. Mov Disord 13:5-10, 1998

26. Madersbacher S, Pedevilla M, Vingers L, Susani M, Marberger M: Effect of high-intensity focused ultrasound on human prostate cancer in vivo. Cancer Res 55:3346-3351, 1995

27. Murata J, Kitagawa M, Uesugi H, Saito H, Iwasaki Y, Kikuchi S, et al: Electrical stimulation of the posterior subthalamic area for the treatment of intractable proximal tremor. $\mathbf{J}$ Neurosurg 99:708-715, 2003

28. Okun MS, Stover NP, Subramanian T, Gearing M, Wainer $\mathrm{BH}$, Holder CA, et al: Complications of gamma knife surgery for Parkinson disease. Arch Neurol 58:1995-2002, 2001

29. Okun MS, Tagliati M, Pourfar M, Fernandez HH, Rodriguez RL, Alterman RL, et al: Management of referred deep brain stimulation failures: a retrospective analysis from 2 movement disorders centers. Arch Neurol 62:1250-1255, 2005

30. Ondo W, Jankovic J, Schwartz K, Almaguer M, Simpson RK: Unilateral thalamic deep brain stimulation for refractory essential tremor and Parkinson's disease tremor. Neurology 51:1063-1069, 1998

31. Plaha P, Khan S, Gill SS: Bilateral stimulation of the caudal zona incerta nucleus for tremor control. J Neurol Neurosurg Psychiatry 79:504-513, 2008

32. Schreglmann SR, Bauer R, Hägele-Link S, Bhatia KP, Natchev P, Wegener N, et al: Unilateral cerebellothalamic tract ablation in essential tremor by MRI-guided focused ultrasound. Neurology 88:1329-1333, 2017

33. Stacy MA, Elble RJ, Ondo WG, Wu SC, Hulihan J: Assessment of interrater and intrarater reliability of the FahnTolosa-Marin Tremor Rating Scale in essential tremor. Mov Disord 22:833-838, 2007

34. Tröster AI, Fields JA, Pahwa R, Wilkinson SB, Strait-Tröster KA, Lyons K, et al: Neuropsychological and quality of life outcome after thalamic stimulation for essential tremor. Neurology 53:1774-1780, 1999

35. Voges J, Hilker R, Bötzel K, Kiening KL, Kloss M, Kupsch A, et al: Thirty days complication rate following surgery performed for deep-brain-stimulation. Mov Disord 22:14861489,2007

36. Wintermark M, Huss DS, Shah BB, Tustison N, Druzgal TJ, Kassell N, et al: Thalamic connectivity in patients with essential tremor treated with MR imaging-guided focused ultrasound: in vivo fiber tracking by using diffusion-tensor MR imaging. Radiology 272:202-209, 2014

37. Young RF, Shumway-Cook A, Vermeulen SS, Grimm P, Blasko J, Posewitz A, et al: Gamma knife radiosurgery as a lesioning technique in movement disorder surgery. J Neurosurg 89:183-193, 1998

38. Zaaroor M, Sinai A, Goldsher D, Eran A, Nassar M, Schlesinger I: Magnetic resonance-guided focused ultrasound thalamotomy for tremor: a report of 30 Parkinson's disease and essential tremor cases. J Neurosurg 128:202210, 2018

39. Zesiewicz TA, Elble R, Louis ED, Hauser RA, Sullivan KL, Dewey RB Jr, et al: Practice parameter: therapies for essential tremor: report of the Quality Standards Subcommittee of the American Academy of Neurology. Neurology 64:20082020, 2005

40. Zhang K, Bhatia S, Oh MY, Cohen D, Angle C, Whiting D: Long-term results of thalamic deep brain stimulation for essential tremor. J Neurosurg 112:1271-1276, 2010

\section{Disclosures}

The authors report no conflict of interest concerning the materials or methods used in this study or the findings specified in this paper.

\section{Author Contributions}

Conception and design: Nanda, Mohammed. Acquisition of data: Nanda, Mohammed. Analysis and interpretation of data: Nanda, Mohammed. Drafting the article: Nanda, Mohammed. Critically revising the article: Nanda, Mohammed. Reviewed submitted version of manuscript: Nanda, Mohammed. Approved the final version of the manuscript on behalf of all authors: Nanda. Statistical analysis: Mohammed. Administrative/technical/material support: all authors. Study supervision: all authors.

\section{Correspondence}

Anil Nanda: Louisiana State University Health Sciences Center, Shreveport, LA. ananda@1suhsc.edu. 